\title{
PENGEMBANGAN PENUNTUN PRAKTIKUM TITRASI ASAM BASA MENGGUNAKAN INDIKATOR ALAMI BERBASIS PENDEKATAN SAINTIFIK
}

\author{
Aisyah Fitri Rusiani Js ${ }^{1}$ dan Lazulva ${ }^{1}$ \\ ${ }^{1}$ Program Studi Pendidikan Kimia, Fakultas Tarbiyah dan Keguruan, UIN Suska Riau, \\ Jl. H. R. Soebrantas Km. 15 Tampan, Pekanbaru, Riau, 28293, Indonesia \\ E-mail:Aisyahfitt411@gmail.com
}

\begin{abstract}
ABSTRAK
Penelitian ini dilatarbelakangi oleh daun Pucuk Merah yang memiliki pigmen zat warna antosianin yang dapat mengalami perubahan warna pada perubahan $\mathrm{pH}$ tertentu. Perubahan warna tersebut dimanfaatkan sebagai indikator $\mathrm{pH}$ alami yang lebih murah dan aman dibandingkan indikator sintesis. Hasil penelitian ini selanjutnya akan dijadikan sebagai media pembelajaran. Penelitian ini bertujuan untuk menghasilkan suatu produk media pembelajaran berupa penuntun praktikum titrasi asam basa menggunakan indikator $\mathrm{pH}$ alami berbasis pendekatan saintifik yang valid dan praktis. Rancangan penelitian menggunakan desain penelitian dan pengembangan dengan tahapan Define, Design, dan Develop. Penelitian ini dilakukan di Madrasah Aliyah Negeri 2 Model Pekanbaru. Instrumen pengumpulan data berupa angket uji validitas dan angket uji praktikalitas, serta dianalisis dengan teknik analisis deskriptif kualitatif dan deskriptif kuantitatif. Hasil penelitian didapatkan bahwa trayek pH ekstrak daun Pucuk Merah yaitu 7,37-9,57 dengan perubahan warna merah muda-kuning. Penggunaan ekstrak daun Pucuk Merah lebih tepat dan lebih cermat digunakan sebagai indikator $\mathrm{pH}$ alami pada titrasi asam kuat basa kuat dibandingkan titrasi asam lemah basa kuat dengan nilai ketepatan $1,7601 \%$ dan nilai kecermatan 0,0848. Media pembelajaran yang dihasilkan dalam bentuk penuntun praktikum memiliki kevalidan $88,36 \%$ (sangat valid) dan tingkat kepraktisan $85,71 \%$ (sangat praktis). Dari hasil tersebut diketahui bahwa penuntun praktikum yang diujicobakan layak dan praktis digunakan sebagai media pembelajaran.
\end{abstract}

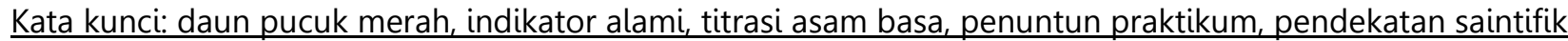

\begin{abstract}
This research was instigated by red shoots containing anthocyanin dye pigments that may change color in certain $\mathrm{pH}$ changes. The color change could be utilized as the natural $\mathrm{pH}$ indicator that was cheap and safe compared with synthetic indicator. The research findings could be utilized as the instructional media. This research aimed at producing a valid and practical instructional media in the form of guide of acid base titration practical work using natural pH indicator Scientific approach based. This research was a Research and Development (R\&D) with defining, designing, and developing steps. This research was administered at State Islamic Senior High School 2 Model Pekanbaru. Validity and practicality test questionnaires were the instruments of collecting the data. Quantitative and qualitative descriptive analyses were the techniques of analyzing the data. The research findings revealed that $p H$ extract trajectory of red shoots was 7.39-9.57 with pink-yellow change. The use of red shoot extract was more appropriate and accurate used as the natural $\mathrm{pH}$ indicator on strong acid base titration compared with low acid base titration, its appropriateness score was $1.7601 \%$ and its accuracy score 0.0848. Instructional Media produced in the form of practical work guide contained $88.36 \%$ validity (very valid) and $85.71 \%$ practicality (very practical). Based the research findings, it could be identified that the practical guide tested was appropriate and practical used as the instructional media.
\end{abstract}

Keywords: red shoots, natural indicator, acid base titration, practical, work guide, scientific approach DOI: https://doi.org/10.15575/jtk.v2i2.1879 


\section{PENDAHULUAN}

Salah satu pembelajaran kimia yang tercantum dalam silabus kimia kelas XI SMA/MA kurikulum 2013 adalah melakukan percobaan titrasi asam basa. Sebagaimana yang disebutkan dalam KD 4.11 yakni merancang, melakukan, dan menyimpulkan serta menyajikan hasil percobaan titrasi asam basa. Percobaan dalam pembelajaran Kimia dilakukan pada kegiatan praktikum. Kegiatan praktikum dalam proses pembelajaran akan membuat peserta didik menjadi lebih yakin atas sesuatu hal dari pada hanya menerima materi pembelajaran yang diberikan guru, peserta didik juga dapat menemukan fakta sendiri dengan indranya, dapat memperkaya pengalaman, mengembangkan sikap ilmiah, dan hasil belajar akan lebih lama tersimpan dalam ingatan peserta didik (Rustaman, 2003).

Kegiatan praktikum akan berjalan dengan baik dan lancar apabila dilengkapi dengan faktor pendukung praktikum seperti alat dan bahan yang diperlukan serta adanya penuntun praktikum. Surat Keputusan Menteri Pendidikan Nasional Nomor: 36/D/O/2001 menjelaskan pengertian penuntun praktikum adalah pedoman pelaksanaan praktikum yang berisi tata cara persiapan, pelaksanaan, analisis data dan pelaporan. Penuntun praktikum yang baik selain memiliki komponen-komponen tersebut juga harus memiliki aspek keselamatan, dapat berupa peringatan yang dituliskan, ataupun lambang yang disertakan (Maharani, 2013).

Penuntun praktikum ditujukan untuk membantu dan menuntun peserta didik agar dapat bekerja secara kontinu dan terarah. Penggunaan penuntun praktikum sangat besar peranannya dalam proses pembelajaran IPA, sehingga seolah-olah buku ini menjadi "buku sakti" ketika seorang guru akan melaksanakan praktikum di laboratorium (Handayani, 2013). Selain itu, juga perlu adanya suatu pendekatan yang sesuai dengan kurikulum 2013 agar kegiatan praktikum dapat terlaksana dengan baik. Salah satu pendekatan yang sesuai dengan langkahlangkah praktikum adalah pendekatan saintifik. Ciri-ciri pendekatan saintifik yaitu mengamati, menanya, mengumpulkan data, mengasosiasi dan mengomunikasikan sangat sesuai apabia diterapkan dalam praktikum (Rahmi, 2014).

Berdasarkan hasil wawancara dengan salah satu guru kimia di MAN 2 Model Pekanbaru diperoleh informasi bahwa kegiatan praktikum titrasi asam basa di sekolah tersebut belum dilakukan secara rutin. Hal ini dikarenakan masalah keterbatasan bahan di laboratorium yaitu bahan indikator sintesis yang berfungsi sebagai penentu titik akhir titrasi. Indikator sintesis yang biasanya digunakan untuk praktikum titrasi asam basa di sekolah adalah indikator fenolftalein dan belum pernah menggunakan indikator dari bahan alami. Hal ini dikarenakan belum adanya pengembangan media pembelajaran yakni penuntun praktikum titrasi asam basa menggunakan indikator $\mathrm{pH}$ alami.

Penuntun praktikum yang ada di sekolah masih bersifat verbal yakni hanya berisikan langkah-langkah praktikum titrasi asam basa menggunakan indikator sintesis. Selain itu, penuntun praktikum titrasi asam basa di sekolah masih berbentuk lembaran aktivitas peserta didik yang hanya berisikan tujuan, landasan teori, alat dan bahan, langkah kerja, tabel hasil pengamatan, dan pertanyaan. Namun belum dilengkapi dengan aspek keselamatan di laboratorium dan belum disusun sesuai dengan pendekatan kurikulum 2013.

Indikator sintesis memiliki kelemahan yakni selain harganya yang mahal, indikator sintesis merupakan bahan kimia yang berbahaya, yang dapat mencemari lingkungan, air, dan tanah, serta membahayakan kesehatan. Contohnya indikator metil jingga yang merupakan pewarna azo, dapat menyebabkan iritasi mata, kulit, dan berpotensi karsinogenik serta dapat mengurangi kebutuhan oksigen dan total organik karbon dalam 
air. Selain itu, menurut Nishikawa indikator fenolftalein pada dosis 25-50 $\mathrm{\mu g} / \mathrm{mL}$ menyebabkan sitotoksik pada sel hati sehingga dapat menurunkan pertumbuhan sel (Jain, 2013).

Dengan melihat permasalahan diatas, maka perlu adanya pengembangan penuntun praktikum pada materi titrasi asam basa menggunakan indikator $\mathrm{pH}$ alami. Indikator $\mathrm{pH}$ alami yang digunakan dalam penelitian ini adalah daun Pucuk Merah (Syzygium campanulatum Korth). Dimana dalam penelitian ini peneliti terlebih dahulu melakukan penelitian di laboratorium PEM Fakultas Pertanian dan Perternakan UIN Suska Riau untuk menentukan trayek $\mathrm{pH}$ dari ekstrak daun Pucuk Merah tersebut. Setelah diketahui trayek $\mathrm{pH}$, selanjutnya ditentukan jenis titrasi yang sesuai untuk trayek $\mathrm{pH}$ yang diperoleh dengan melihat tingkat akurasi dan presisinya. Kemudian barulah jenis titrasi yang sesuai untuk trayek $\mathrm{pH}$ tersebut, yang peneliti input kedalam penuntun praktikum yang dikembangkan. Oleh karena itu, disini peneliti tertarik untuk melakukan penelitian dengan rumusan masalah berapakah trayek $\mathrm{pH}$ dari indikator $\mathrm{pH}$ alami ekstrak daun pucuk merah, bagaimana tingkat akurasi dan presisi dari indikator $\mathrm{pH}$ alami ekstrak daun pucuk merah, serta bagaimana tingkat validitas dan praktikalitas penuntun praktikum yang dikembangkan. Adapun tujuan penelitian ini adalah untuk mengetahui trayek $\mathrm{pH}$ dari indikator $\mathrm{pH}$ alami ekstrak daun pucuk merah, mengetahui tingkat akurasi dan presisi dari indikator $\mathrm{pH}$ alami ekstrak daun pucuk merah serta untuk mengembangkan penuntun praktikum titrasi asam basa yang valid dan praktis menggunakan indikator $\mathrm{pH}$ alami ekstrak daun pucuk merah sehingga kegiatan praktikum titrasi asam basa dapat dilaksanakan di sekolah.

Indikator $\mathrm{pH}$ alami merupakan bahanbahan yang mempunyai zat warna yang umumnya berasal dari tumbuh-tumbuhan (akar, daun, bunga, buah, atau biji) dan dapat dibuat melalui ekstraksi dengan pelarut yang sesuai (Mulyono, 2008).
Penggunaan ekstrak tumbuhan sebagai indikator $\mathrm{pH}$ alami untuk titrasi asam basa didasari kandungan tumbuhan yakni pigmen warna antosianin yang dapat berubah warna pada tiap perubahan $\mathrm{pH}$ tertentu (Marwati, 2012).

Indikator $\mathrm{pH}$ alami yang digunakan dalam penelitian ini adalah daun Pucuk Merah (Syzygium campanulatum Korth). Keberadaan daun Pucuk Merah tersebar luas di daerah Indonesia termasuk negara tropis lainnya. Pucuk Merah adalah jenis tanaman hias yang tergolong dalam family Myrtaceae. Tanaman ini dikenal dengan nama Pucuk Merah karena tunas daun yang baru tumbuh pada bagian pucuk berwarna merah menyala. Tanaman hias ini sering dipangkas dan dibentuk sedemikian rupa, sehingga banyak pucuk daun yang masih berwarna merah ikut terbuang dan kemudian menjadi sampah. Padahal menurut penelitian terdahulu yang dilakukan oleh Muhammad Iqbal, diketahui bahwa daun Pucuk Merah yang mengandung pigmen antosianin yang dapat berubah warna pada larutan dengan $\mathrm{pH}$ tertentu (lqbal, 2014). Dalam pH asam antosianin berwarna merah orange sedangkan dalam $\mathrm{pH}$ basa antosianin berwarna biru-ungu atau kadang-kadang kuning (Murni, 2015).

\section{METODE PENELITIAN}

Penelitian ini menggunakan metode penelitian dan pengembangan (Research and Development) model 4-D (four-D) terdiri atas empat tahapan yaitu define, design, develop dan disseminate, atau diadaptasi menjadi model 4-P yaitu pendefinisian, perancangan, pengembangan dan penyebaran (Trianto, 2014). Namun, dalam penelitian ini peneliti hanya sampai tahap ketiga yaitu sampai pada develop atau pengembangan produk. Pada tahap define dilakukan persiapan dalam membuat penuntun praktikum seperti analisis ujung depan, analisis peserta didik, analisis tugas, analisis konsep, dan perumusan tujuan pembelajaran. Pada tahap design diawali dengan merancang dan melakukan penelitian di laboratorium untuk 
membuktikan bahwa daun Pucuk Merah dapat digunakan sebagai indikator $\mathrm{pH}$ alami dalam praktikum titrasi asam basa, kemudian merancang format dan melakukan perancangan awal penuntun praktikum. Pada tahap develop dilakukan pengembangan penuntun praktikum titrasi asam basa yang akan diuji kevalidan dan kepraktisannya, hingga dihasilkan penuntun praktikum yang valid dan praktis.

Teknik pengumpulan data yang digunakan dalam penelitian ini adalah angket dengan skala perhitungan rating scale. Angket yang digunakan dalam pengumpulan data ini adalah angket uji validitas yang diberikan kepada 1 orang ahli materi, 1 orang ahli media dan angket uji praktikalitas yang diberikan kepada 5 orang guru Kimia di MAN 2 Model Pekanbaru. Adapun tabel skala angketnya sebagai berikut:

Tabel 1. Skala Angket untuk Ahli Materi, Media, dan Guru Kimia

\begin{tabular}{|c|c|}
\hline Jawaban & Skor \\
\hline Sangat Baik & 5 \\
\hline Baik & 4 \\
\hline Cukup Baik & 3 \\
\hline Kurang Baik & 2 \\
\hline Tidak Baik & 1 \\
\hline
\end{tabular}

Teknik pengolahan data dilakukan dengan cara menghitung skor maksimal ideal, menghitung skor yang diperoleh, kemudian menghitung persentasi keidealan dengan rumus :

Persentase keidealan $=$

$\frac{\text { Skor yang diperoleh }}{\text { skor maksimal ideal }} \times 100 \%$

Hasil persentase keidealan kemudian diinterpretasikan dalam pengertian kualitatif berdasarkan tabel dibawah ini:

Tabel 2. Interpretasi nilai validitas dan praktikalitas

\begin{tabular}{|c|c|}
\hline $\begin{array}{c}\text { Interval } \\
(\%)\end{array}$ & Kriteria \\
\hline $81-100$ & Sangat Valid/Sangat Praktis \\
\hline $61-80$ & Valid/Praktis \\
\hline $41-60$ & Cukup Valid/ Cukup Praktis \\
\hline
\end{tabular}

\begin{tabular}{|c|c|}
\hline $21-40$ & Kurang Valid/ Kurang Praktis \\
\hline $0-20$ & Tidak Valid/ Tidak Praktis \\
\hline
\end{tabular}

\section{HASIL DAN PEMBAHASAN}

Pada dasarnya penelitian ini dilakukan untuk mengembangkan penuntun praktikum kimia SMA/MA kelas XI pada materi titrasi asam basa. Penuntun praktikum dibuat berdasarkan hasil analisis pada tahap define, design, dan develop. Pada tahap define diketahui bahwa kegiatan praktikum titrasi asam basa belum dilaksanakan secara rutin disekolah dikarenakan keterbatasan bahan indikator sintesis. Selain itu, diketahui bahwa peserta didik SMA/MA kelas XI rata-rata berusia 15-17 tahun. Menurut Nurhasna Wati peserta didik SMA/MA cenderung menyukai buku yang memiliki desain warna dan gambar yang menarik sehingga peserta didik tertarik untuk membaca dan mempelajarinya (Nurhasna, 2000). Oleh karena itu penuntun praktikum yang akan dikembangkan dilengkapi dengan warna dan gambar yang menarik.

Pada tahap design, dihasilkan rancangan penuntun praktikum yang diawali dengan melakukan percobaan di laboratorium Patologi, Entomologi, dan Mikrobiologi Fakultas Pertanian dan Peternakan UIN Suska Riau. Percobaan mulai dari pembuatan ekstrak daun Pucuk Merah menggunakan pelarut akuades $60^{\circ} \mathrm{C}$ yang dimaserasi selama 24 jam dengan perbandingan antara sampel dan pelarut 1:10. Diperoleh hasil ekstrak daun Pucuk Merah berwarna merah tua.

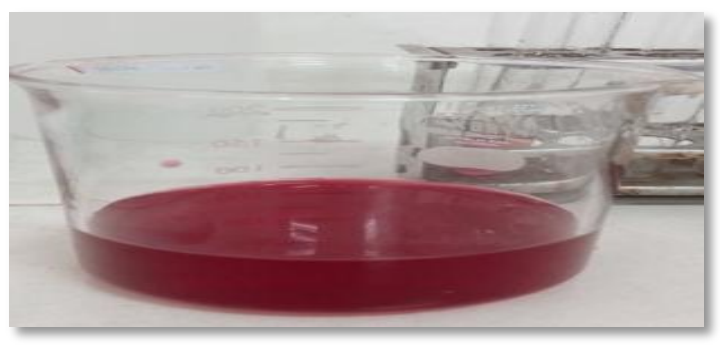

Gambar 1. Ekstrak daun Pucuk Merah.

Ekstrak selanjutnya di uji menggunakan spektrofotometer UV-Vis Cary 50 ConcVarian, hasil absorbansi maksimum yang 
diperoleh menunjukkan pada panjang gelombang $510 \mathrm{~nm}$ sebesar $0.0241 \mathrm{~A}$. dimana panjang gelombang tersebut berada pada range daerah serapan spektrum sinar tampak dari antosianin yaitu pada panjang gelombang 490-550 nm (Santoni, 2013). Sehingga dapat disimpulkan bahwa sampel ekstrak daun Pucuk Merah positif mengandung antosianin.

Langkah selanjutnya adalah penentuan trayek $\mathrm{pH}$. Trayek $\mathrm{pH}$ ditentukan dari data pergeseran panjang gelombang maksimum yang drastis disertai perubahan yang signifikan dari nilai absorbansi setiap pH secara berturut-turut (Padmaningrum, 2011). Pada tabel 3 dapat dilihat dari larutan buffer $\mathrm{pH} 7,37-9,57$ terjadi pergeseran panjang gelombang maksimum yang drastis disertai perubahan nilai absorbansi yang signifikan. Jadi, trayek $\mathrm{pH}$ ekstrak daun Pucuk Merah yang didapatkan menggunakan spektrofotometer UV-Vis Cary 50 Conc-Varian yaitu 7,37-9,57 dengan perubahan warna merah mudahkuning. Sehingga dapat disimpulkan bahwa ekstrak daun Pucuk Merah dapat dijadikan sebagai indikator $\mathrm{pH}$ alami.

Tabel 3. Data pergeseran panjang gelombang maksimum ekstrak daun Pucuk Merah

\begin{tabular}{|c|c|c|}
\hline $\mathbf{p H}$ & $\begin{array}{c}\text { Panjang } \\
\text { Gelombang Maks } \\
\text { (nm) }\end{array}$ & bsorbansi (A) \\
\hline 0.72 & 516 & 1.038 \\
\hline 1.84 & 514 & 0.744 \\
\hline 2.81 & 516 & 0.411 \\
\hline 3.83 & 516 & 0.322 \\
\hline 4.79 & 524 & 0.462 \\
\hline 5.76 & 534 & 0.522 \\
\hline 6.79 & 545 & 0.730 \\
\hline $\mathbf{7 . 3 7}$ & $\mathbf{5 2 1}$ & $\mathbf{0 . 4 2 2}$ \\
\hline $\mathbf{8 . 5 7}$ & $\mathbf{5 5 0}$ & $\mathbf{0 . 7 6 4}$ \\
\hline $\mathbf{9 . 5 7}$ & $\mathbf{5 8 7}$ & $\mathbf{1 . 2 0 1}$ \\
\hline 10.66 & 586 & 0.945 \\
\hline 11.60 & 576 & 0.655 \\
\hline 12.44 & 467 & 2.614 \\
\hline 13.03 & 476 & 3.214 \\
\hline
\end{tabular}

Berdasarkan trayek $\mathrm{pH}$ yang didapatkan, indikator $\mathrm{pH}$ alami dari daun Pucuk Merah dapat digunakan dalam titrasi asam basa jenis titrasi asam kuat-basa-kuat dan titrasi asam lemah-basa kuat. Hal ini dikarenakan trayek $\mathrm{pH}$ 7,37-9,57 memiliki kisaran $\mathrm{pH}$ yang sama atau mendekati titik ekivalen titrasi asam kuat-basa-kuat (titik ekivalen=7) dan titrasi asam lemah-basa kuat (titik ekuivalen>7) (Lisa, 2013). Indikator sintetis yang digunakan sebagai pembanding adalah fenolftalein yang memiliki trayek $\mathrm{pH}$ 8,00-10,00 dengan perubahan warna tak berwarna-merah muda.

Selanjutnya dilakukan titrasi dengan membandingkan indikator yang digunakan yaitu indikator $\mathrm{pH}$ alami dengan indikator sintesis, masing-masing dilakukan titrasi sebanyak 10 kali pengulangan. Diperoleh tingkat ketepatan (akurasi) penggunaan ekstrak daun Pucuk Merah sebagai indikator $\mathrm{pH}$ alami pada titrasi asam basa dinyatakan sedang, yaitu pada titrasi asam kuat basa kuat sebesar $1,7601 \%$ dan pada titrasi asam lemah basa kuat sebesar 2,0742\%. Sedangkan kecermatannya, penggunaan ekstrak daun Pucuk Merah sebagai indikator $\mathrm{pH}$ alami titrasi asam kuat basa kuat sebesar 0,9167\% dan pada titrasi asam lemah basa kuat sebesar 1,1550\%. Sehingga penggunaan ekstrak daun Pucuk Merah lebih tepat dan lebih cermat sebagai indikator $\mathrm{pH}$ alami titrasi asam kuat basa kuat. Titrasi asam kuat basa kuat inilah yang hanya akan diadopsi kedalam penuntun praktikum yang dikembangkan.

Karakteristik penuntun praktikum yang dikembangkan selain menggunakan bahan alami yang aman bagi kesehatan dan lingkungan serta mudah diperoleh dalam kehidupan sehari-hari, juga memiliki karakteristik lain yakni disusun berbasis pendekatan saintifik. Penuntun Praktikum yang didesain berdasarkan pendekatan saintifik sangat sesuai diterapkan dalam praktikum.

Pendekatan saintifik terdiri dari mengamati, menanya, mengumpulkan data, mengasosiasi, dan mengomunikasikan. Dalam kegiatan mengamati peserta didik mengamati 
gambar yang berhubungan dengan apa yang akan dipraktikumkan. Menanya, dalam kegiatan menanya berisi bagian tempat yang disediakan untuk peserta didik memberikan atau membuat pertanyaan berdasarkan apa yang telah diamati dari proses mengamati. Kegiatan mengumpulkan data berisi tabel yang harus diisi oleh peserta didik setelah melaksanakan praktikum. Kegiatan mengasosiasi berisi soal-soal yang berkaitan dengan apa yang dipraktikumkan oleh peserta didik, dimana soal-soal tersebut dapat membantu peserta didik dalam menarik kesimpulan dari kegiatan praktikum yang dilakukan. Selanjutkan kegiatan mengomunikasikan, kegiatan ini berisi format laporan praktikum yang selanjutnya laporan tersebut dipresentasikan secara perkelompok didepan kelas.

Langkah selanjutnya pada tahap design adalah melakukan perancangan awal penuntun praktikum yang terdiri dari 3 komponen yaitu bagian pendahuluan, berisi sampul (cover), halaman judul, kata pengantar, daftar isi, petunjuk penggunaan penuntun praktikum, tata tertib bekerja di laboratorium, keselamatan kerja di laboratorium, cara penanganan kecelakaan kerja di laboratorium dan daftar simbol tanda bahaya bahan Kimia.

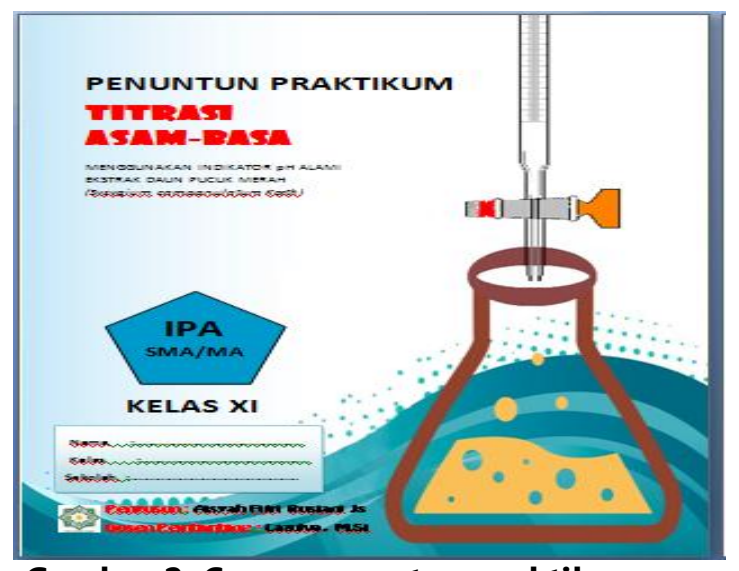

Gambar 2. Cover penuntun praktikum

Bagian isi terdiri dari kegiatan praktikum. Kegiatan praktikum berisi judul praktikum, tujuan praktikum, landasan teori, proses mengamati, menanya, mengumpulkan data, mengasosiasi

dan mengomunikasikan.

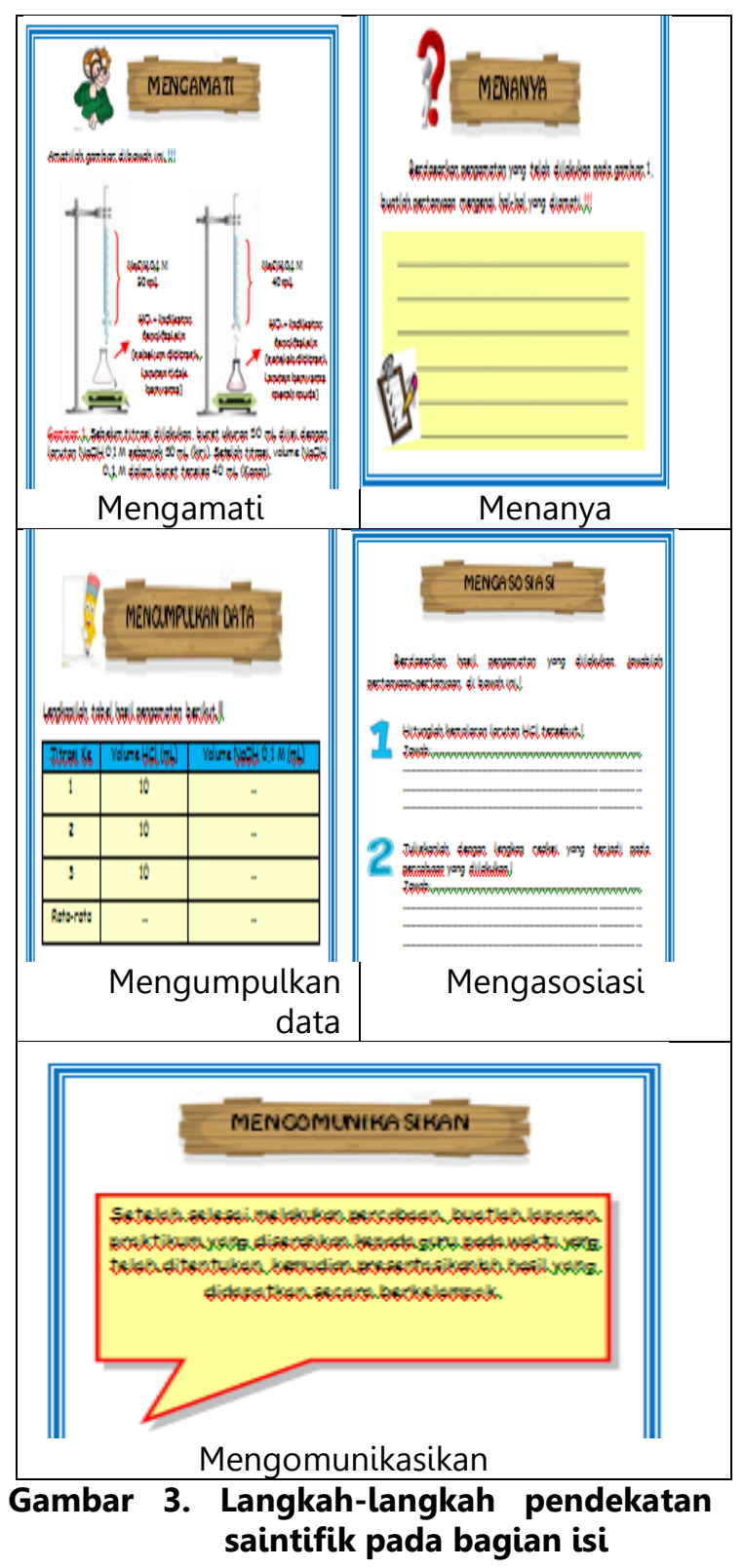

Bagian isi juga dilengkapi dengan informasi kimia, ketentuan penyusunan laporan praktikum dan glosarium. Bagian penutup berisi daftar kepustakaan dari berbagai sumber yang digunakan dalam pembuatan penuntun praktikum.

Bagian penutup berisi daftar kepustakaan dari berbagai sumber yang digunakan dalam pembuatan penuntun praktikum. 
Tabel 4. Hasil Uji Validasi Media Pembelajaran oleh Ahli Media

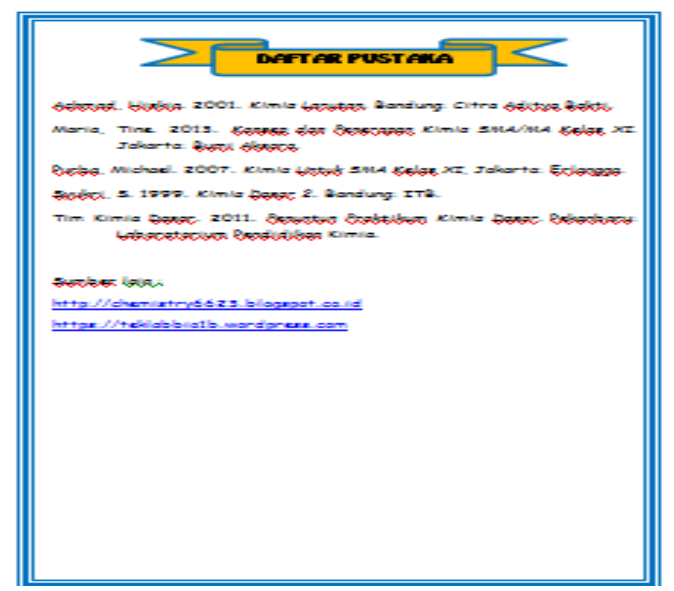

Gambar 4. Daftar pustaka pada bagian penutup

Penuntun praktikum ini dibuat menggunakan aplikasi Microsoft Word 2007. Namun bisa juga menggunakan Microsoft Word 2010, Microsoft Word 2013, ataupun Microsoft Word 2016. Aplikasi ini sangat mudah diperoleh, dan hampir terdapat disetiap komputer ataupun laptop. Selain itu aplikasi Microsoft Word dapat digunakan secara offline tanpa jaringan internet sehingga tidak perlu mengeluarkan biaya yang mahal untuk menggunakan aplikasi ini. Penuntun praktikum ini di buat menggunakan size $A 4$, margins left $3 \mathrm{~cm}$, top $2 \mathrm{~cm}$, right $2 \mathrm{~cm}$, dan bottom $2 \mathrm{~cm}$. Orientation portrait. Theme font Comic Sans MS, Arial Rounded MT Bold, dan Showcard Gothic, dengan font size 12.

Pada tahap develop, dilakukan pengembangan penuntun praktikum titrasi asam basa yang akan diuji kevalidannya kepada 1 orang ahli materi dan 1 orang ahli media, serta diuji kepraktisannya kepada 5 orang guru Kimia MAN 2 Model Pekanbaru. Ahli media dalam validasi produk penuntun praktikum adalah Bapak Hanafi, M.Pd dosen Fakultas Tarbiyah dan Keguruan Universitas Islam Negeri Sultan Syarif Kasim Riau. Validasi ahli media dilakukan dengan menunjukkan dan menjelaskan tentang produk media pembelajaran penuntun praktikum beserta lembar penilaian berupa angket. Hasil yang diperoleh dapat dilihat pada tabel 4 berikut:

\begin{tabular}{|l|l|l|l|}
\hline No & Pernyataan & $\begin{array}{c}\text { Nilai } \\
\text { Validasi }\end{array}$ & Kriteria \\
\hline 1 & $\begin{array}{l}\text { Kejelasan } \\
\text { Kalimat } \\
\text { dan tingkat } \\
\text { keterbacaan }\end{array}$ & $80 \%$ & Valid \\
\hline 2 & $\begin{array}{l}\text { Tampilan fisik } \\
\text { penuntun } \\
\text { praktikum }\end{array}$ & $80 \%$ & Valid \\
\hline 3 & $\begin{array}{l}\text { Kelengkapan } \\
\text { penuntun } \\
\text { praktikum }\end{array}$ & $93,33 \%$ & Sangat valid \\
\hline \multicolumn{2}{|l}{ Jumlah Keseluruhan } & $84 \%$ & Sangat valid \\
\hline
\end{tabular}

Tabel 4 merupakan hasil uji kevalidan media pembelajaran berupa penuntun praktikum oleh validator ahli media. Angket yang diberikan kepada validator berisi sebanyak 3 aspek pernyataan. Dari tabel 4 terlihat bahwa kejelasan kalimat dan tingkat keterbacaan serta Tampilan fisik penuntun praktikum dikategorikan valid dengan persentase kevaliditannya sebesar 80\%. Sedangkan kelengkapan penuntun praktikum dikategorikan sangat valid dengan persentase kevaliditannya sebesar 93,33\%. Sehingga didapatkan persentase kevalidan media pembelajaran secara keseluruhan sebesar $84 \%$ artinya media pembelajaran berupa penuntun praktikum dikategorikan sangat valid dan layak untuk diujicobakan di sekolah.

Ahli materi dalam validasi produk penuntun praktikum adalah Bapak Lazulva, M.Si dan Ibu Zona Octarya, M.Si, dosen Fakultas Tarbiyah dan Keguruan Universitas Islam Negeri Sultan Syarif Kasim Riau. Validasi ahli materi dilakukan dengan menunjukkan dan menjelaskan tentang produk media pembelajaran penuntun praktikum beserta lembar penilaian berupa angket. Hasil yang diperoleh dapat dilihat pada tabel 5 berikut: 
Tabel 5. Hasil Uji Validasi Media Pembelajaran oleh Validator Ahli Materi

\begin{tabular}{|l|l|l|l|}
\hline No & Pernyataan & $\begin{array}{l}\text { Nilai } \\
\text { Prak- } \\
\text { tikalitas }\end{array}$ & Kriteria \\
\hline 1 & $\begin{array}{l}\text { Kebenaran } \\
\text { konsep }\end{array}$ & $90,66 \%$ & $\begin{array}{l}\text { Sangat } \\
\text { praktis }\end{array}$ \\
\hline 2 & $\begin{array}{l}\text { Keterlaksanaan } \\
\text { kegiatan }\end{array}$ & $86 \%$ & $\begin{array}{l}\text { Sangat } \\
\text { praktis }\end{array}$ \\
\hline 3 & $\begin{array}{l}\text { Muatan } \\
\text { kurikulum }\end{array}$ & $88 \%$ & $\begin{array}{l}\text { Sangat } \\
\text { praktis }\end{array}$ \\
\hline 4 & $\begin{array}{l}\text { Evaluasi } \\
\text { belajar }\end{array}$ & $88 \%$ & $\begin{array}{l}\text { Sangat } \\
\text { praktis }\end{array}$ \\
\hline 5 & $\begin{array}{l}\text { Kejelasan } \\
\text { kalimat dan } \\
\text { tingkat } \\
\text { keterbacaan }\end{array}$ & $81 \%$ & $\begin{array}{l}\text { Sangat } \\
\text { praktis }\end{array}$ \\
\hline 6 & $\begin{array}{l}\text { Tampilan fisik } \\
\text { penuntun } \\
\text { praktikum }\end{array}$ & $85,33 \%$ & $\begin{array}{l}\text { Sangat } \\
\text { praktis }\end{array}$ \\
\hline 7 & $\begin{array}{l}\text { Kelengkapan } \\
\text { penuntun } \\
\text { praktikum }\end{array}$ & $84 \%$ & $\begin{array}{l}\text { Sangat } \\
\text { praktis }\end{array}$ \\
\hline $\begin{array}{l}\text { Jumlah } \\
\text { Keseluruhan }\end{array}$ & $85,71 \%$ & $\begin{array}{l}\text { Sangat } \\
\text { praktis }\end{array}$ \\
\hline
\end{tabular}

Tabel 5 merupakan hasil uji kevalidan media pembelajaran berupa penuntun praktikum oleh validator ahli materi. Angket yang diberikan kepada validator berisi sebanyak 4 aspek pernyataan. Dari tabel 5 terlihat bahwa kebenaran konsep, keterlaksanaan kegiatan, muatan kurikulum, dan evaluasi belajar dikategorikan sangat valid dengan persentase kevaliditannya masing-masing sebesar 93,33\%, 95\%, 85\%, dan 95\%. Sehingga didapatkan persentase kevalidan media pembelajaran secara keseluruhan sebesar 92,72\% artinya media pembelajaran berupa penuntun praktikum dikategorikan sangat valid dan layak untuk diujicobakan di sekolah.

Penuntun praktikum yang telah divalidasi oleh validator, selanjutnya diujicobakan ke sekolah. Uji coba dilakukan kepada lima orang guru Kimia di MAN 2 Model Pekanbaru. Hasil uji coba ini digunakan untuk mengetahui praktikalitas produk yang dikembangkan. Hasil uji coba praktikalitas diperoleh melalui pengisian angket untuk mengetahui respon dari guru Kimia terhadap penuntun praktikum yang dikembangkan. Angket uji coba ini diisi oleh guru Kimia setelah membaca dan memahami penuntun praktikum pada materi titrasi asam basa. Hasil yang diperoleh dapat dilihat pada tabel 6 berikut:

Tabel 6. Hasil Uji Kepraktisan Media Pembelajaran Guru Kimia

\begin{tabular}{|l|l|l|l|}
\hline No & Pernyataan & $\begin{array}{l}\text { Nilai } \\
\text { Validasi }\end{array}$ & Kriteria \\
\hline 1 & $\begin{array}{l}\text { Kebenaran } \\
\text { konsep }\end{array}$ & $93,33 \%$ & $\begin{array}{l}\text { Sangat } \\
\text { valid }\end{array}$ \\
\hline 2 & $\begin{array}{l}\text { Keterlaksanaan } \\
\text { kegiatan }\end{array}$ & $95 \%$ & $\begin{array}{l}\text { Sangat } \\
\text { valid }\end{array}$ \\
\hline 3 & $\begin{array}{l}\text { Muatan } \\
\text { kurikulum }\end{array}$ & $85 \%$ & $\begin{array}{l}\text { Sangat } \\
\text { valid }\end{array}$ \\
\hline 4 & $\begin{array}{l}\text { Evaluasi } \\
\text { belajar }\end{array}$ & $95 \%$ & $\begin{array}{l}\text { Sangat } \\
\text { valid }\end{array}$ \\
\hline Jumlah keseluruhan & $92,72 \%$ & $\begin{array}{l}\text { Sangat } \\
\text { valid }\end{array}$ \\
\hline
\end{tabular}

Tabel 6 merupakan hasil uji coba terhadap lima orang guru Kimia untuk mengetahui apakah penuntun praktikum yang dihasilkan praktis untuk digunakan sebagai media pembelajaran untuk peserta didik dan sebagai acuan bagi guru. Angket yang diberikan kepada guru Kimia terdiri 7 aspek pernyataan.

Dari tabel 6 terlihat bahwa kebenaran konsep, keterlaksanaan kegiatan, muatan kurikulum, evaluasi belajar, kejelasan kalimat dan tingkat keterbacaan, tampilan fisik penuntun praktikum, dan kelengkapan penuntun praktikum dikategorikan sangat praktis dengan persentase keidealan berturut-turut yaitu $90,66 \%, 86 \%, 88 \%, 88 \%$, 81\% dan $85,33 \%$ dan $84 \%$. Sehingga didapatkan persentase kepraktisan media pembelajaran secara keseluruhan sebesar $85,71 \%$ artinya media pembelajaran berupa penuntun praktikum temasuk dalam kategori sangat praktis atau layak untuk diujicobakan ke peserta didik SMA/MA dalam proses pembelajaran titrasi asam basa di sekolah.

Walaupun penuntun praktikum sudah dinyatakan praktis atau layak diujicobakan, namun penulis tetap melakukan revisi sesuai dengan komentar dan saran dari 
guru Kimia agar penuntun praktikum Kimia yang dihasilkan lebih baik lagi. Berikut beberapa komentar dan saran oleh guru Kimia terhadap penuntun praktikum yang telah dikembangkan.

Tabel. 7. Komentar dan saran oleh guru kimia terhadap penuntun praktikum yang dikembangkan

\begin{tabular}{|c|c|}
\hline \multicolumn{2}{|c|}{ Uji Praktikalitas di Sekolah } \\
\hline Saran & Perbaikan \\
\hline $\begin{array}{lr}\text { KI dan } & \mathrm{KD} \\
\text { dilampirkan } & \text { dalam } \\
\text { penuntun } & \\
\text { praktikum. } & \end{array}$ & $\begin{array}{l}\text { KI dan KD sudah } \\
\text { dilampirkan dalam } \\
\text { penuntun praktikum. }\end{array}$ \\
\hline $\begin{array}{l}\text { Kalimat keterangan } \\
\text { gambar pada } \\
\text { bagian mengamati } \\
\text { perlu direvisi, } \\
\text { ditambahkan } \\
\text { kalimat sebelum } \\
\text { dan setelah titrasi. }\end{array}$ & $\begin{array}{l}\text { Kalimat keterangan } \\
\text { gambar pada bagian } \\
\text { mengamati sudah } \\
\text { ditambahkan kalimat } \\
\text { sebelum dan setelah } \\
\text { titrasi. }\end{array}$ \\
\hline $\begin{array}{lr}\text { Kalimat } & \text { perintah } \\
\text { pada } & \text { bagian } \\
\text { menanya } & \text { perlu } \\
\text { direvisi, } & \text { diganti titik } \\
\text { menjadi } & \text { koma } \\
\text { karena } & \text { kalimatnya } \\
\text { rancu. } & \end{array}$ & 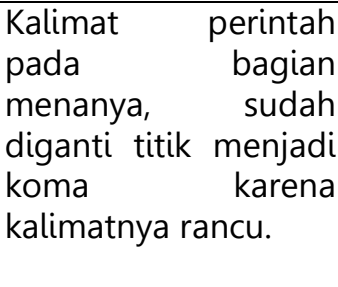 \\
\hline
\end{tabular}

Berdasarkan hasil penilaian yang didapatkan pada uji validitas dan praktikalitas, dapat disimpulkan bahwa penuntun praktikum pada materi titrasi asam basa menggunakan indikator $\mathrm{pH}$ alami berbasis pendekatan saintifik sangat valid dan sangat praktis dengan persentasenya berturut-turut sebesar $88,36 \%$ dan $85,71 \%$. Hal ini berarti bahwa penuntun praktikum pada materi titrasi asam basa menggunakan indikator $\mathrm{pH}$ alami dapat dijadikan sebagai media pembelajaran dan layak untuk diuji cobakan ke peserta didik.

\section{KESIMPULAN}

Berdasarkan hasil penelitian dapat disimpulkan bahwa (1) Tingkat ketepatan (akurasi) penggunaan ekstrak daun Pucuk Merah sebagai indikator $\mathrm{pH}$ alami pada titrasi asam basa dinyatakan sedang, yaitu pada titrasi asam kuat basa kuat sebesar $1,7601 \%$ dan pada titrasi asam lemah basa kuat sebesar 2,0742\%. Sedangkan kecermatannya (presisi), penggunaan ekstrak daun Pucuk Merah sebagai indikator $\mathrm{pH}$ alami titrasi asam kuat basa kuat sebesar 0,9167\% dan pada titrasi asam lemah basa kuat sebesar 1,1550\%. Sehingga penggunaan ekstrak daun Pucuk Merah lebih tepat dan lebih cermat sebagai indikator $\mathrm{pH}$ alami titrasi asam kuat basa kuat. (2) Penuntun praktikum pada materi titrasi asam basa menggunakan indikator $\mathrm{pH}$ alami berbasis pendekatan saintifik dinyatakan valid oleh ahli desain media dan ahli materi pembelajaran dengan kategori sangat valid yaitu dengan persentase $88,36 \%$. Hal ini terlihat dari persentase rata-rata analisis angket ahli media dan ahli materi pembelajaran berturut-turut yaitu $84 \%$ dan $92,72 \%$. (3) Penuntun praktikum pada materi titrasi asam basa menggunakan indikator $\mathrm{pH}$ alami berbasis pendekatan saintifik dinyatakan praktis oleh guru-guru Kimia di sekolah dengan kategori sangat praktis yaitu dengan persentase $85,71 \%$.

\section{DAFTAR PUSTAKA}

HAM, Mulyono. (2008). Membuat Reagen Kimia. Jakarta: Bumi Aksara.

Handayani, Lena Putri., Farida F., Azwir Anhar. (2013). Pengembangan Buku Penuntun Praktikum IPA Berbasis Inkuiri Terbimbing untuk SMP Kelas VII Semester II. Jurnal Pendidikan Biologi PPs UNP, 69-76.

Iqbal, Muhammad. (2014). Identifikasi Antosianin dari Daun Pucuk Merah (Syzygium campanulatum Korth). Skripsi, Fakultas FMIPA Kimia: Universitas Andalas.

Jain, Pramod Kumar., Pushpa Jain., Prajvi Jain. (2013). Petal Sap of Delonix Regia as a Substitute for Hazardous Internal Indicators in Volumetric Analysis. Jurnal Biosci. Biotech. Res. Comm, 6(2), 186-189.

\footnotetext{
Maharani, Maylinda Uti. (2013). Pengembangan Petunjuk Praktikum
} 
IPA Terpadu Tema Fotosintesis Berbasis Learning Cycle untuk Siswa SMP. Skripsi, Fakultas Matematika dan Ilmu Pengetahuan Alam: Universitas Negeri Malang.

Marwati, Siti. (2012). Ekstraksi dan Preparasi Zat Warna Alami sebagai Indikator Titrasi Asam Basa. Prosiding Seminar Nasional Penelitian, Pendidikan dan Penerapan MIPA.

Murni, Hutdia Putri. (2015). Identifikasi Senyawa Organik Bahan Alam pada Daun Pucuk Merah (Syzygium oleana)". Makalah Praktikum Kimia Organik II. Padang: FMIPA UNP.

Padmaningrum, Regina Tutik. (2011). Karakter Ekstrak Zat Warna Daun Rheo Discolor sebagai Indikator Titrasi Asam Basa. Prosiding Seminar Nasional Penelitian, Pendidikan dan Penerapan MIPA, 229-234.

Rahmi, Mutiara., Hairida., Robi Putra. (2014). Implementasi Pendekatan Scientific Berbasis Lesson Study dalam Praktikum Hukum

Perbandingan Tetap. Jurnal Pendidikan Kimia FKIP UNTAN, 3(7), 1-11.

Rustaman. (2003). Common Text Book Strategi Belajar Mengajar Biologi. Bandung: Jica.

Santoni, Adlis., Djaswir D, Sukmaning S. (2013). Isolasi Antosianin dari Buah Pucuk Merah (Syzygium campanulatum korth.) serta Pengujian Antioksidan dan Aplikasi sebagai Pewarna Alami. Prosiding Semirata FMIPA Universitas Lampung, 1-10.

Trianto. (2014). Mendesain Model Pembelajaran Inovatif, Progresif, dan Kontekstual. Jakarta: Prenadamedia Group.

Utami, Lisa. (2013). Kimia Analitik I. Pekanbaru: Benteng Media.
Wati, Nurhasna. (2000). Media Pembelajaran. Pekanbaru: Yayasan Pustaka Riau. 